\title{
NONLINEAR GENERALIZED QUASI-VARIATIONAL INEQUALITIES: A FIXED POINT APPROACH
}

\author{
RAVi P. AGARWAL AND DONAL O'REGAN
}

Abstract. The existence of solutions to quasi-variational inequalities is established using recent fixed point theory.

Mathematics subject classification (2000): 47H10, 47J20.

Key words and phrases: Quasi-variational inequalities, fixed point theory, Hausdorff topological vector space.

\section{REFERENCES}

[1] R. P. AgarWAL AND D. O'REgan, KKM maps and fixed point theory, Proc. Sixth Int. Conf. on Nonlinear Functional Analysis and Applications, Korea 2000, Nova Science Publishers Inc., New York., p. 11-13.

[2] R. P. Agarwal And D. O'REgan, Fixed point theory for admissible multimaps, Dynamic Systems and Applications, to appear.

[3] C. D. Aliprantis AND K. C. Border, Infinite dimensional analysis, Springer Verlag, Berlin, 1994.

[4] H. BEN-El-MechaieKH AND G. IsAC, A general variational inequality and applications, C. R. Math. Rep. Acad. Sci. Canada, 16 (1994), 235-240.

[5] M. P. CHEN AND S. PARK, A unified approach to generalized quasi-variational inequalities, Comm. Applied Anal., 4 (1997), 103-118.

[6] P. HaRTMAn And G. STAMPACCHIA, On some nonlinear elliptic differential equations, Acta Math., 115 (1966), 271-310.

[7] J. L. Lions And G. Stampacchia, Variational inequalities, Comm. Pure Appl. Math., 20 (1967), 493-519.

[8] D. O'REgAn, Fixed points, multivalued inequalities, control problems and differential inclusions on proximate retracts, Math. Proc. Royal Irish Academy, 98A (1998), 107-120.

[9] D. O'REgAn, Fixed point theorems for the $\mathscr{B}^{k}$-admissible maps of Park, Applicable Analysis, 79 (2001), 173-185.

[10] D. O'Regan, Furi-Pera type theorems for the $\mathscr{U}_{c}^{k}$-admissible maps of Park, Math. Proc. Royal Irish Academy, to appear.

[11] D. O'REGAN, A unified fixed point theory for countably P-concentrative multimaps, Applicable Analysis, 81 (2002), 565-574

[12] S. PARK, A unified fixed point theory of multimaps on topological vector spaces, J. Korean Math. Soc., 35 (1998), 803-829.

[13] S. PARK, Fixed points of approximable maps, Proc. Amer. Math. Soc., 124 (1996), 3109-3114.

[14] R. SAIGAL, Extensions of the generalized complementarity problem, Math. Op. Research, 1 (1976), 260-266. 